\title{
Autologous Platelet Concentrate Preparations in Dentistry
}

\section{Ola M Ezzatt*}

Associate Professor of Oral Medicine and Periodontology, Faculty of Dentistry, Ain-Shams University, Egypt

Received: 阱 August 27, 2018; Published: 阱 September 07, 2018

*Corresponding author: Ola M Ezzatt, Associate Professor of Oral Medicine and Periodontology, Faculty of Dentistry Ain-Shams University Cairo, Egypt

\begin{abstract}
Platelet concentrates are blood derivatives prepared from the patient's own blood in which the activated platelets become trapped within a fibrin matrix scaffold and release growth factors and cytokines involved in the key processes of tissue regeneration; including cell proliferation and differentiation, extracellular matrix synthesis, chemotaxis and angiogenesis. These processes found to promote healing in both soft and hard tissues which led to successful therapeutic applications in medical and dental fields over the last two decades. Based on differences in centrifugation speeds and times, adding chemicals, and the selection of supernatants and precipitates; various preparations have been produced with different fibrin network structures, leukocyte content and growth factors and subsequent different physical and physiological properties and applications. The biology behind, the protocols for preparation and the science based evidence applications of different platelet concentrates in various fields of dentistry will be reviewed.
\end{abstract}

Keywords: Platelet Concentrates; Periodontal Regeneration; Centrifugation Protocol

\section{Introduction}

\section{Biological Rational for the Platelets Concentrates Use in Regenerative Dentistry}

The knowledge of wound healing has been greatly enhanced by the identification and understanding of the role of blood clot and growth factors in the healing process [1]; During the initial phase of wound healing, platelets interact with the fibrin clot to form a hemostatic plug and to create a temporary scaffold to capture cytokines and support and stimulate cell migration and proliferation through the release of certain growth factors from platelet's $\alpha$ granules upon activation [2]. (Figure 1) represents diagrammatic presentation of major molecules and growth factors produced from activated platelet [3]. The main growth and differentiation factors released from platelet aggregates their target cells, and function are summarized in (Table 1) [3-5].

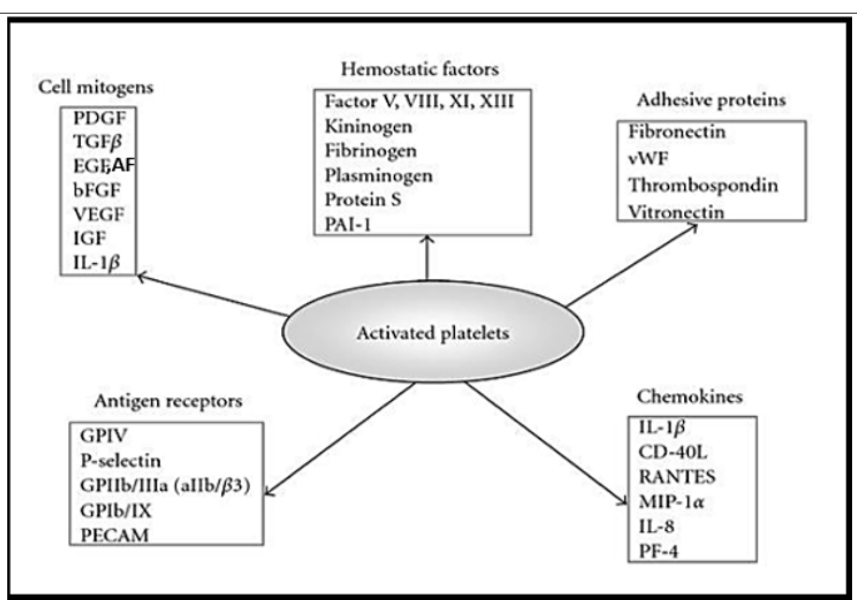

Figure 1: Growth factors and molecules produced from activated platelet; PDGF, platelet-derived growth factor; TGF $\beta$, transforming growth factor $\beta$; EGF, endothelial growth factor; $\mathrm{AF}$, angiogenesis factor; bFGF, fibroblast growth factor; VEGF, vascular endothelial growth factor; IGF, insulin-like growth factor; IL-1 $\beta$, interleukin-1 $\beta$; PAI-1, plasminogen activator inhibitor 1 ; vWF, von Willebrand factor; GP, glycoproteins; PECAM, platelet and endothelial cell adhesion molecule; CD40L, CD40 ligand (CD154); RANTES, regulated on activation, normal T-cell expressed and secreted; MIP-1 $\alpha$, macrophage inflammation protein $1 \alpha$; IL-8, interleukin-8; PF4, platelet factor 4 
Table 1: Summary of main actions of platelets' growth factors and molecules.

\begin{tabular}{|c|c|c|}
\hline Growth factor /Molecule & Target & Action \\
\hline PDGF & $\begin{array}{l}\text { Fibroblasts, smooth muscle cells, } \\
\text { macrophages/neutrophils }\end{array}$ & $\begin{array}{l}\text { Stimulates chemotaxis/mitogenesis in fibroblast/glial/smooth muscle cells; } \\
\text { regulates collagenase secretion/collagen synthesis }\end{array}$ \\
\hline TGF $\beta$ & $\begin{array}{l}\text { Fibroblasts, marrow stem cells, } \\
\text { endothelial cells, epithelial cells, } \\
\text { preosteoblasts. }\end{array}$ & $\begin{array}{l}\text { Stimulates/inhibits endothelial, fibroblastic, and osteoblastic mitogenesis; } \\
\text { regulates collagen synthesis/collagenase secretion; regulates mitogenic effects } \\
\text { of other growth factors; stimulates endothelial chemotaxis and angiogenesis. }\end{array}$ \\
\hline EGF & $\begin{array}{l}\text { Fibroblasts, endothelial cells, epithelial } \\
\text { cells. }\end{array}$ & $\begin{array}{l}\text { Stimulates endothelial chemotaxis/angiogenesis; regulates collagenase } \\
\text { secretion; epithelial/mesenchymal mitogenesis }\end{array}$ \\
\hline $\mathrm{AF}$ & Endothelial cells & $\begin{array}{l}\text { Increases angiogenesis and vessel permeability; stimulates mitogenesis for } \\
\text { endothelial cells by direct or indirect actions; upregulate several cytokines and } \\
\text { growth factors, including IGF-1, TGF, PDGF, bFGF, EGF, and IL-1 } \beta \text {. }\end{array}$ \\
\hline bFGF & $\begin{array}{l}\text { Fibroblasts, endothelial cells, epithelial } \\
\text { cells. }\end{array}$ & Increases angiogenesis, epithelization and fibroblastic mitogenesis \\
\hline VEGF & $\begin{array}{l}\text { Endothelial cells macrophages/ } \\
\text { neutrophils }\end{array}$ & $\begin{array}{c}\text { Stimulate angiogenesis; migration and mitosis of endothelial cells; creation } \\
\text { of blood vessel lumen; chemotactic for macrophages and granulocytes; } \\
\text { Vasodilation (indirectly by release of nitrous oxide) }\end{array}$ \\
\hline IGF & Fibroblasts, osteoblasts, chondrocytes & $\begin{array}{l}\text { Stimulates cartilage growth, bone matrix formation, and replication of } \\
\text { preosteoblasts and osteoblasts; acts as an autocrine and paracrine factor; in } \\
\text { combination with PDGF can enhance the rate and quality of wound healing }\end{array}$ \\
\hline PF4 & Fibroblasts, neutrophils & Chemoattractant for neutrophils and fibroblasts; potent antiheparin agent. \\
\hline RANTES & Lymphocytes and monocytes & Recruits monocytes and T cells \\
\hline CD40L & Endothelial cells, & $\begin{array}{l}\text { monocytes, neutrophils, B cells and fibroblast } \\
\text { Increases the stability of new platelet aggregates, activate vascular } \\
\text { inflammatory mechanisms by inducing production of ROS, enhancing } \\
\text { expression of adhesion molecules Vascular Cell Adhesion Molecule-1 (VCAM-1), } \\
\text { Intercellular AdhesionMolecule-1 (ICAM-1), and E-selectin in endothelial cells, } \\
\text { and increasing secretion of cytokines, chemokines, matrix metalloproteinases } \\
\text { (MMPs) } \\
\text { vWF, PECAM }\end{array}$ \\
\hline $\begin{array}{l}\text { vWF, PECAM } \\
\text { GPs, P-Selectin }\end{array}$ & $\begin{array}{l}\text { P-Selectin Platelets, endothelial cells, } \\
\text { collagen }\end{array}$ & $\begin{array}{l}\text { Ensures a stable anchorage with subendothelial matrix by direct interaction } \\
\text { with collagen }\end{array}$ \\
\hline Fibrinogen, Vitronectin, & Fibronectin Thrombospondin1 & $\begin{array}{l}\text { Activated platelets, and with ECM Components } \\
\text { Enhances platelet adhesion and local aggregation, stimulate attachment and } \\
\text { proliferation of osteoblasts and fibroblast. Enhance angiogenesis. }\end{array}$ \\
\hline $\begin{array}{c}\text { Fibronectin } \\
\text { Thrombospondin } 1\end{array}$ & Osteoblasts, Fibroblasts & Bone mineralization, cell-matrix interactions, and collagen binding \\
\hline Other Chemokines & Leukocytes & $\begin{array}{l}\text { Attract leukocytes and further activate other platelets, regulate inflammatory } \\
\text { pathways. }\end{array}$ \\
\hline
\end{tabular}

Platelets begin actively secreting these proteins within ten minutes of clotting, with more than $95 \%$ of the pre-synthesized growth factors secreted within one hour. After the initial burst of growth factors, the platelets synthesize and secrete additional factors for the remaining several days of their life span $[6,7]$. Normally, blood contains approximately $200000 / \mu$ l of platelets. The volume of the plasma fraction of autologous blood having a platelet concentration above baseline [ $\begin{array}{lll}1 & 407 & 640 \mu \text { l (about five }\end{array}$ times higher than that of the normal)] is defined as platelets rich or pure concentrate [8]. The original concept behind the use of platelet concentrates was based on the fact that autologous concentrated platelets and growth factors could be collected in plasma solutions to mimic the terminal stage of the natural coagulation cascade, which is, the formation of fibrin clot and release of growth factors that could then be utilized in a surgical site as natural scaffold and to promote local healing and lost tissue regeneration [9]. This autologous extract of the circulating blood tissue is considered tissues themselves, and not pharmaceutical preparations thus eliminated concerns about immunogenic reactions and disease transmission [5].

Later the inclusion of leukocytes in this autologous blood derivatives have been addressed not only because of their immune and antibacterial properties, but also because of their contribution in the wound healing process through regulation of local factors, cell proliferation and differentiation. Moreover, leukocyte populations had a strong influence on the release of some growth factors, particularly TGF $\beta 1$ [10-13]. The fibrin content and architecture of the product were studied also which found to affect the physical properties and thus clinical applications and considerably influence the strength and the growth factor trapping/release potential of the product [11]. Based on differences in centrifugation speeds and times, adding chemicals, and the selection of supernatants and precipitates; various preparations have been produced with different fibrin network structures, leukocyte content and growth 
factors and subsequent different physical and physiological properties and applications $[14,15]$.

\section{History and Classification of Platelet Concentrates and Plasma Derived Preparations}

The history of these preparations started in 1970 with the research works of Matras about the "Fibrin glues" used to improve skin wound healing in a rat model based on the concept that fibrin matrix is the final result of the reaction chains of the coagulation and the first matrix of healing [16] and represented one of the first biological surgical adjuvants [17]. Later between (1975-1979) new strategies insisted in the role of platelets within the fibrin gel and upgraded the concept for the use of blood extracts, termed "Plateletfibrinogen-thrombin mixtures or platelets gels" [18]. which then applied in different fields of oral and maxillofacial surgeries starting from $1997[19,20]$. From that moment, the number of publications and system available on the market grew quickly. However, all these products were termed "Platelet-Rich Plasma (PRP)". Anitua later developed "Plasma rich in growth factors (PRGF)" by modifying the procedure of PRP preparation [21]. All previous preparations required extrinsic clotting factor to initiate the clotting pathways and were considered the (First Generation) of platelet concentrates [22].

Another form of platelet concentrates which was self-clotted and was developed by Choukroun J et al. in France in 2006 and termed "Platelet-Rich Fibrin (PRF)" due to the strong fibrin gel polymerization of the preparation and was considered the (Second Generation) $[23,24]$. In the last years authors started pointing out that these platelet concentrates were also associated with various forms of circulating cells particularly leukocytes that may be a key element in healing process. For this reason, the "Leukocyte-and Platelet-Rich Fibrin (L-PRF)" was often described as an (Optimized Blood Clot) [25] and allowed to define new therapeutic principles: NTR (Natural Tissue Regeneration) [26].

Later on, number of technologies and protocols were developed to improve the characterization of the preparations in terms of release duration and content of growth factors or cells and physical properties including "Advanced and Injectable PRF (A-PRF, i-PRF)" $[27,28]$. The "Titanium-prepared platelet-rich fibrin (T-PRF)", "Concentrated growth factors (CGF)" and "Advanced Fibrin Glue (AFG)" are another modified form of PRF prepared by changing centrifugation protocol or material of collection tubes $[29,30]$. The long history of these products was always associated with confusions, mostly related to the lack of specific terminology, characterization and classification of the many products that were tested in the last 40 years, thus their clinical relevance is largely debated, as the literature on the topic is often confused and contradictory [31]. The first classification was proposed in 2009 [31]. This classification system was largely cited, advocated, and validated by a multi-disciplinary consensus conference published in 2012 [22]. The POSEIDO (Periodontology, Oral Surgery, Esthetic and Implant Dentistry Organization) hold it as its guidelines for all publications on the topic in 2013 [32].

This classification separated the products based on 2 key parameters; the presence of cell content (mostly leukocytes) and the fibrin architecture. This separation allowed defining 4 main families of the products [31]:

Pure Platelet-Rich Plasma (P-PRP) or Leukocyte-Poor Platelet-Rich Plasma: These preparations are without leukocytes and with a low-density fibrin network after activation so can be used as injectable liquid solutions or in an activated gel form to be placed or injected on wound or surgical site.

Leukocyte-and Platelet-Rich Plasma (L-PRP): These preparations are with leukocytes and with a low-density fibrin network after activation so can be used as injectable liquid solutions or in an activated gel form to be placed or injected on wound or surgical site. In this family the largest number of commercial or experimental systems exists. Many technologies and commercial kits were developed to produce (L-PRP) with minimal handling of the blood samples and maximum standardization of the preparations.

Pure Platelet-Rich Fibrin (P-PRF) or Leukocyte-Poor Platelet-Rich Fibrin: These preparations without leukocytes and with a high-density fibrin network and only exist in a strongly activated gel form, so cannot be injected or used like traditional fibrin glues. However, they can be handled like fibrin membranes or solid materials for other applications.

Leukocyte and Platelet-Rich Fibrin (L-PRF): These preparations with leukocytes and with a high-density fibrin network and only exist in a strongly activated gel form and cannot be injected. However, because of their strong fibrin matrix, they can be handled like a real solid material for many applications. The technique was initially developed and evaluated as an open-access technique, based on the concept of one-step centrifugation of blood without anticoagulant and without blood activator [23].

\section{Protocols and Characterizations for Different Preparations}

Platelet-Rich Plasma Preparations (PRP): Generally, PRP is prepared via a two-step centrifugation preparation of anticoagulated blood sample (Usually using EDTA or $1.0 \mathrm{ml}$ of acid citrate dextrose-ACD- solution). During the first step (Soft Spin) of centrifugation ( $300 \mathrm{~g}$ for $5 \mathrm{~min}$ at $12^{\circ} \mathrm{C}$ or $240 \mathrm{~g}$ for $8 \mathrm{~min}$ at $16^{\circ} \mathrm{C}$ ), three layers are demarcated: red blood cells (RBCs) on the bottom, 'buffy coat' (BC) middle layer that contains platelets and leukocyte and platelet poor plasma (PPP) plasma on top. For production of Pure PRP (P-PRP), PPP and superficial BC are transferred to another tube, then centrifuged for a second time (Hard Spin) to ensure proper plasma separation $\left(700 \mathrm{~g}\right.$ for $17 \mathrm{~min}$ at $\left.12^{\circ} \mathrm{C}\right)$, most of the PPP layer is discarded. The final P-PRP concentrate consists of an undetermined fraction of $\mathrm{BC}$ (containing a large number of platelets) suspended in some fibrin-rich plasma.

For production of Leukocyte-rich PRP (L-PRP), PPP, the entire $\mathrm{BC}$ layer and some residual RBCs are transferred to another tube. After hard spin centrifugation, the PPP is discarded. The final L-PRP consists of the entire $\mathrm{BC}$, which contains most of the platelets and leukocytes, and residual RBCs suspended in some fibrin-rich plasma (Figure 2) [33]. Coagulation cascade then activated by adding thrombin to any of these products, permitted to clot at $37^{\circ} \mathrm{C}$ 
before injection in patient. Plasma Rich in Growth Factors (PRGF) is a type of (P-PRP) using special single spin protocol (PRGF-Endoret technology) first described by Dr. Anitua and were most commonly used in oral and maxillofacial surgeries [34]. Blood samples ( 9.6 $\mathrm{mL}$ per tube) were collected using $18 \mathrm{G}$ needles in citrated tubes (contained $0.2 \mathrm{ml}$ sodium citrate). The tubes then centrifuged at $2270 \mathrm{rpm}$ for $8 \mathrm{~min}$ at room temperature. After centrifugation, the blood sample was layered into the following four distinctive layers 1) $0.5 \mathrm{~mL}$ Plasma poor in growth factors (PPGFs) =F1 in the uppermost part of the tube, 2) $0.5 \mathrm{~mL}$ Plasma with growth factors $(\mathrm{PGFs})=\mathrm{F} 2,3) 0.5 \mathrm{~mL}(\mathrm{PRGF})=\mathrm{F} 3$ located immediately above the red blood cell portion in the tube, 4) Red blood cell concentrate layer. The PPGF was eliminated and the PRGF was separated with $500 \mu \mathrm{L}$ pipettes and transported to an independent tube then activated using $50 \mu \mathrm{L}$ of $10 \%$ calcium chloride to be used as liquid or incubated for 20 minutes in $37^{\circ} \mathrm{C}$ to produce easy to handle gelatinous layer (PRGF) as fibrin scaffold or membrane, so Anitua simplified the preparation protocol for PRP and replaced animal derived thrombin with calcium for clotting (Figure 3) [31]. Despite the advantages and wide clinical applications described for different PRP preparations; the several handling steps, addition of chemicals, the lack of standardized protocol and different centrifugation devices and tubes lead to wide range of characterization and properties and a relatively high variability in clinical results $[9,33,35]$.

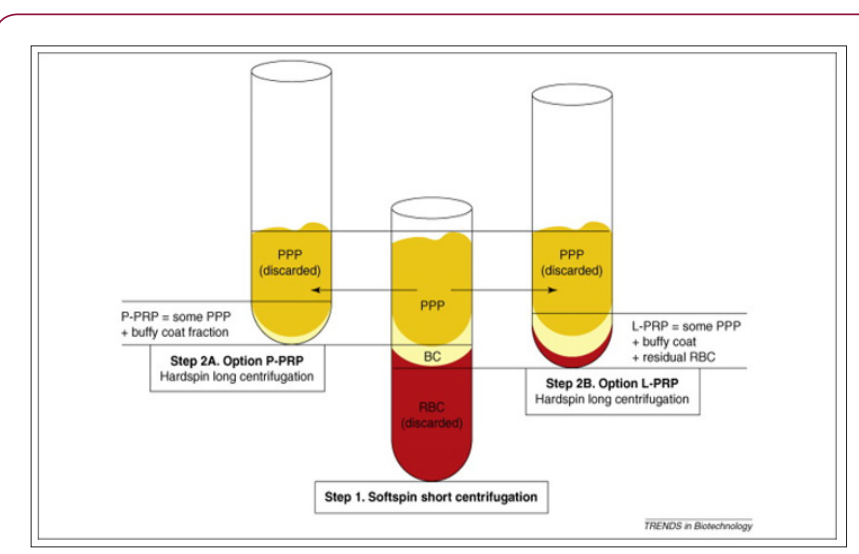

Figure 2: Preparation of P-PRP and L-PRP.

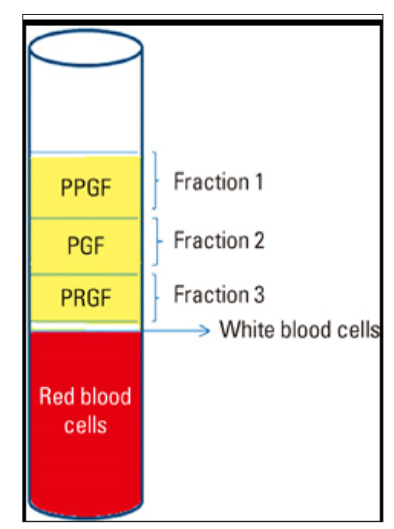

Figure 3: Plasma Fractions Produced in Preparation of PRGF.
Platelet-Rich Fibrin Preparations (PRF): Choukroun's Pure Platelet-rich fibrin (P-PRF) belongs to a new generation of platelet concentrates, with simplified processing and without biochemical blood handling. The research on PRF was led by Dr. Joseph Choukroun [24,36]. A standard protocol for PRF preparation should be followed to obtain proper quantity and quality of the fibrin matrix, platelets, and growth factors; 24 gauge butterfly needle is used for $9 \mathrm{ml}$ blood collection in sterile glass coated plastic tubes without anticoagulant which are immediately centrifuged at $3000 \mathrm{rpm}$ for $10 \mathrm{~min}$. During the centrifugation process, when the blood gets in contact with the test tube wall the platelet gets activated leading to the initiation of coagulation cascade. After centrifugation, the resultant product consists of three layers. The top most layer consisting of acellular PPP (platelet poor plasma), PRF clot in the middle and RBCs at the bottom of the test tube. The fibrin clot obtained after centrifugation is removed from the tube and the attached red blood cells scraped off from it and discarded. PRF can also be prepared in the form of a membrane by squeezing out the fluids present in the fibrin clot (Figure 4) [37].

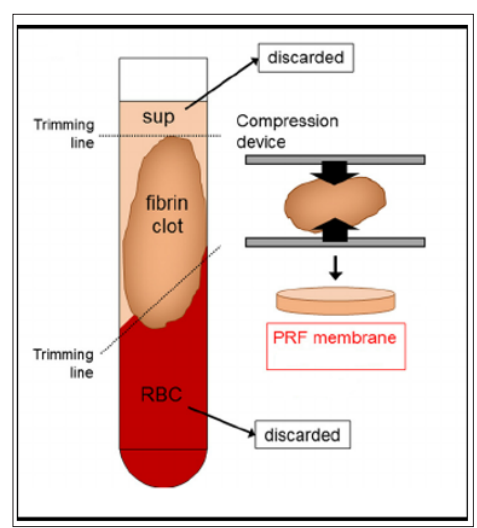

Figure 4: Preparation of Choukroun's PRF.

Leukocyte Platelet-Rich Fibrin (L-PRF): The L-PRF clot or membrane are modified PRF to contain most of the platelets and leukocytes present in the initial blood harvest plus the platelet growth factors and stem cells that are also trapped within the fibrin network with enhanced strength [38]. It is produced by modification of initial technique of (P-PRF); Blood should be collected quickly in $9 \mathrm{ml}$ glass-coated plastic tubes (less than 20 seconds per tube) and immediately (before 1 minute) centrifuged in Intra-Spin centrifuge at room temperature (2700 rpm for 12 minutes) to produce L-PRF clots. The clots can be collected carefully into a sterile adapted surgical box and compressed into membranes, remain as fibrin plug or mixed with particulate bone for preparation of sticky bone [39].

Advanced Platelet-Rich Fibrin (A-PRF): It is another modification from (P-PRF) in which they found that decreasing the rpm while increasing the centrifugation time (1300 rpm, 14 minutes) gave an enhanced presence of neutrophilic granulocytes in the distal part of the clot, increased and prolonged release of growth factors. Accordingly, this might be able to influence the differentiation of host macrophages and macrophages within the clot after implantation. Thus, they suggest this would influence bone and soft tissue regeneration, especially through the presence 
of monocytes/macrophages and their growth factors [40]. However other study comparing A-PRF with L-PRF found contrast results regarding both growth factor release and physical properties of the membrane (Figure 5) [38].

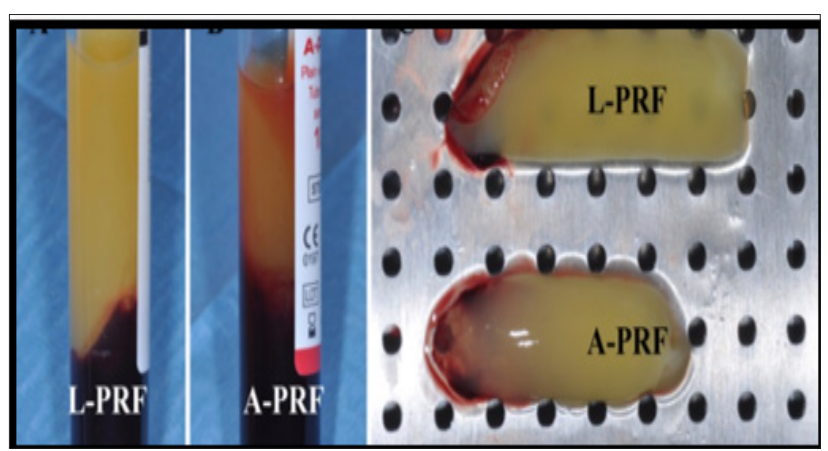

Figure 5: L- PRF and A-PRF clots and membranes.

Injectable Platelet-Rich Fibrin (i-PRF): The development of this injectable formulation of PRF was with the aim of delivering to clinicians an easy to use platelet concentrates in liquid formulation which can be either utilized alone or combined easily with various biomaterials. Taking advantage of slower and shorter centrifugation speeds, a higher presence of regenerative cells with higher concentrations of growth factors can be observed when compared to other formulations of PRF [41]. The i-PRF is produced as follows: $10 \mathrm{~mL}$ of whole blood collected in plain vacuum tubes without anticoagulant was immediately centrifuged at $700 \mathrm{rpm}$ for $3 \mathrm{~min}$. The $1 \mathrm{~mL}$ upper plasma layer was then collected using 21 gauge needle and designated as i-PRF [28]. Addition of i-PRF to particulate bone will lead to polymerization in $15 \mathrm{~min}$ to produce red colored sticky bone (Figure 6).

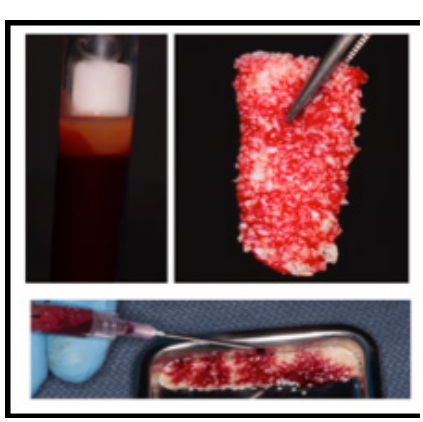

Figure 6: Sticky bone formation using i- PRF.

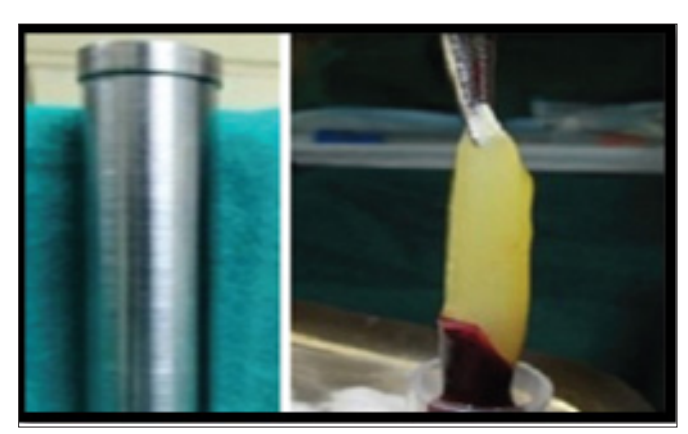

Figure 7: Titanium tubes used for preparation of T-PRF.
Titanium Platelet-Rich Fibrin (T-PRF): Based on the hypothesis that titanium may be a more efficient platelet activator than silica, for preparing L-PRF Tunali et al in 2014, introduced a new product called (Titanium- prepared PRF) in which the $9 \mathrm{ml}$ of blood was quickly collected in grade IV titanium tubes, and the tubes were immediately centrifuged at $2800 \mathrm{rpm}$ for 12 minutes and found more organized, thicker and longer fibrin network (Figure 7) [42].

Concentrated Growth Factors Preparation (CGF): The alternative centrifugation protocol used for this preparation (Intravenous blood samples from the patients is placed in a standard, 10-ml non-anticoagulant centrifuge tubes and accelerated for 30 s, centrifuged at $2700 \mathrm{rpm}$ for $4 \mathrm{~min}, 2400 \mathrm{rpm}$ for $4 \mathrm{~min}, 2700$ rpm for $4 \mathrm{~min}$, and $3000 \mathrm{rpm}$ for $3 \mathrm{~min}$, and decelerated for $36 \mathrm{~s}$ to stop as adjusted automatically by centrifugal device) suggested the separation of a fibrin matrix which is much denser, larger and richer in growth factors; Three layers were observed in the tube: red blood cell layer at the bottom, platelet-deprived plasma layer (without cell) at the top, and fibrin gel with concentrated growth factor and platelet aggregation in the middle. First, the uppermost platelet-deprived fraction was removed with a sterile syringe. The layer in the form of a membrane containing the concentrated growth membrane was held with the aid of a hemostatic clamp, separated from the red blood cell layer by cutting with a pair of scissors and then pressed to form a membrane (Figure 8) [43].

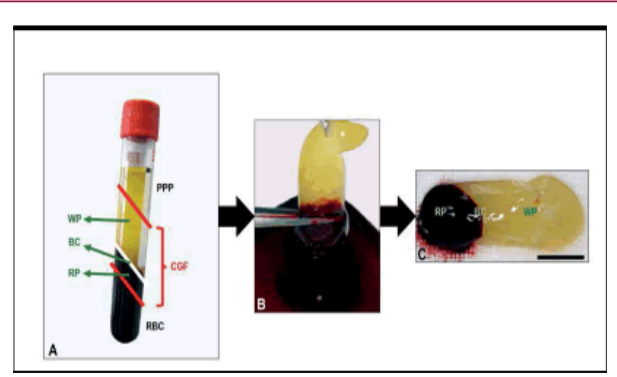

Figure 8: CGF preparation.

Autologous Fibrin Glue (AFG) and Sticky Bone: A concept of fabricating growth factors-enriched bone graft matrix (also known as "sticky bone") using autologous fibrin glue (AFG) has been demonstrated since 2010; To obtain autologous fibrin glue, 2060CC of blood in non-coated tubes is centrifuged at $2400-2700 \mathrm{rpm}$ for $2 \mathrm{~min}$. Out of the two layers obtained, the deeper layer is RBC's and the superficial layer is AFG. This AFG is then extracted using a syringe and mixed with particulate bone powder and allowed to rest for 5-10 min for polymerization, which results in a yellow coloured mass called sticky bone [44] (Figure 9).

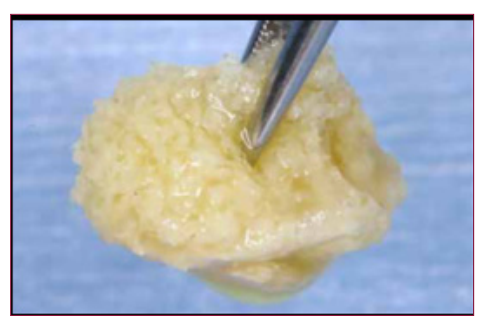

Figure 9: Preparation of sticky bone using AFG. 
Most of the second-generation platelet concentrates has shown promising results providing an ideal base for wound healing and regeneration of tissues because it combined the fibrin sealant properties with the growth factors. Several researchers have studied and compared the characterizations of different platelets concentrates in order to speculate their best clinical applications $[35,37,38,40,43,45-48]$. Regarding the rate of growth factor release; activating platelets through the clot formation in PRP initiates the secretion of $70 \%$ of their stored growth factors within 10 minutes and $100 \%$ within the first hour [35]. While in PRGF the growth factor delivery is diffusion controlled with a rapid initial release by $30 \%$ of the bioactive content after $1 \mathrm{~h}$ and a steady state release with almost $70 \%$ of the growth factor content is delivered and retained almost $30 \%$ of the amount of the growth factors after 8 days. In particular, the kinetics of PDGF and VEGF release from PRGF clot is linear reaching a plateau after the 3rd day [49]. PRF preparations seems to have a sustained release of growth factors in a period between 1 and 4 weeks40. While CGF showed linear release of PDGF and VEGF in 3rd and 6th days respectively then reached plateau till 8th day [43].

Regarding the concentration of growth factors, cytokines and cell content; in a recent study by Masuki et al. 2016 comparing PRP, PRGF, A-PRF and CGF found that. The order of growth factor levels (TGF- 1 1, PDGF, VEGF) were A-PRF $\geq$ CGF > PRP >> PRGF. PRGF preparations contained the lowest amounts of growth factors. Leukocyte content were similarly concentrated in these plateletconcentrated preparations (PRP: 5.51-fold, CGF: 8.63-fold, A-PRF: 11.87-fold) compared to whole blood. However, only an exception was PRGF preparations; leukocytes were almost completely eliminated. While platelet contents were highest in A-PRF followed by CGF, PRP and PRGF. IL-1 $\beta$ in PRGF preparations was under detectable levels, while it showed a similar level in other three preparations. For IL-6, in contrast, there were no differences among preparations [50]. Another study by Kobayashi et al. 2016 further stated that the advantage of PRP is the release of significantly higher proteins at earlier time points whereas PRF displayed a continual and steady release of growth factors over a 10-day period and (A-PRF) released significantly higher total quantities of growth factors when compared to traditional PRF4.

Comparing the biological effects of different platelet concentrates; PRP preparations enhanced osteogenesis by inducing and stimulating cells such as osteoblasts, whether derived from the local defect site or from autologous graft tissue (osteoconductive). Furthermore, PRP in its gel form also provided a scaffold for incoming cells and growth factors, allowing the local physiological mechanism to take over but in an accelerated fashion. However, PRF released autologous growth factors gradually and expressed stronger and more durable effect on proliferation and differentiation of rat osteoblasts than PRP51. The apparent order of potency effect on the proliferation of human periosteal cells was $\mathrm{PRP}>\mathrm{CGF}>\mathrm{A}-\mathrm{PRF}>\mathrm{PRGF}$ while that of angiogenic potency is CGF/ PRF> PRP/PRGF [45]. In addition to L-PRP's and PRF's direct effects on proliferation, differentiation, and angiogenesis, they also affect wound healing indirectly via the chemotactic recruitment of cells and local control of the inflammatory environment. Highlighting the role of leukocyte content of these preparations $[13,36]$.

The physical properties of different platelet concentrates can justify their possible clinical applications PRF and A-PRF membranes could serve as a resorbable membrane for GTR because they have a complex architecture of strong fibrin matrix with favorable mechanical properties that can prevent the migration of non-desirable cells into bone defect and providing a space that allows the immigration of osteogenic and angiogenic cells and permits the underlying blood clot to mineralize [37], While CGF had larger and denser fibrin network constituted by thin and thick fibrin with multiple regenerative elements trapped among the fibrin network. The sticky bone forms strongly inter-linked fibrin network mixed with the graft material that is usually self-stable, so the bone loss on the defect during healing period is minimized without use of bone tack or titanium mesh [43].

The effect of platelet concentrates on stem cells have been recently investigated and reviewed concluding that PRP and stem cells (bone marrow mesenchymal stem cells, adipose stem cells and dental derived stem cells) can be employed in conjunction for tissue regeneration and PRP was able to enhance also stem cell proliferation and adhesion in dose dependent manner, and contributed to an increase in cell expansion rates by reducing cell death through reduction in Bcl-2 expression and apoptosis [52]. Furthermore, the PRF preparations beside the previously mentioned properties of PRP it possessed an optimal threedimensional (3-D) structure that favours the delivery and support of cell sheets at a specific area that has been destroyed $[53,54]$. It is expected that the explanation of the mixed clinical results reported in the literature will be found in the cell population and activation of these products in vivo because platelets are being active during only a very short time period and growth factors probably being released, consumed locally or dissolved in the blood flow in the minutes or hours after their release [50].

\section{Review of Clinical Applications and Outcomes in Regenerative Dentistry}

Platelet concentrates have been widely used to accelerate tissue regeneration and repair in dental and medical fields [55-57]. Regarding the use PRP preparations a group of recent systematic reviews and meta-analysis reported that there is no significant difference in bone augmentation in favour of the adjunctive use of PRP in bone formation around implant [58] and there were no enough human studies that strongly support the benefit of using PRP in sinus augmentation procedures [59]. However, for infrabony regenerative treatment: a systematic review and metaanalysis of 14 RCT's that is recently published in 2018 concluded that the combination of bone grafts with PRP was always producing better clinical results in terms of CAL gain and pocket reduction than the adjunctive use of membranes after short- and longer term reassessment regardless of the flap procedure and the high heterogeneity among studies [60].

An earlier review of the role of platelet-rich plasma in soft tissue root-coverage procedures in 2008 had concluded that the 
potential benefits of PRP in root-coverage procedures may be improved esthetics, decreased patient morbidity, and accelerated wound healing while the effects of PRP in enhancing root-coverage is not conclusive due to inadequate clinical evidence [60]. Later few clinical trials reported controversial results that the additional application of PRP with connective tissue graft does significantly increase the width of keratinized gingiva and gain in CAL [61]. Other studies suggested that PRP can provide only an early healing of soft tissues with no clinically measurable enhancements on the final therapeutic outcomes [62,63]. Regarding the use of autologous platelet concentrates in implant and reconstructive surgery, the literature is particularly dense about the use of the various forms of Platelet-Rich Plasma (PRP) - Pure Platelet-Rich Plasma (P-PRP) or Leukocyte- and Platelet-Rich Plasma (L-PRP) - but still limited about Platelet-Rich Fibrin (PRF) subfamilies. Various plasma derivatives have been used in during implant placement (particularly as surface treatment for the stimulation of osseointegration), the treatment of peri-implant bone defects (after peri-implantitis, during implantation in an insufficient bone volume or during immediate post-extraction or post-avulsion implantation), the sinus lift procedures and various complex implant-supported treatments.

Other potential applications of the platelet concentrates are also highlighted in maxillofacial reconstructive surgery, for the treatment of patients using bisphosphonates, anticoagulants or with posttumoral irradiated maxilla $[19,29,64-66]$. For the use of PRP with stem cells; PRP stimulated the cellular proliferation of pluripotent cells only in early stages of bone healing as reported in vitro studies, thus it was recommended to incorporate bone morphogenic protein since it can increase the osteogenic differentiation of bone and also to develop a suitable carrier which can degrade slowly to deliver the PRP for longer period to enhance late stage bone healing [67]. PRF preparations showed compelling data in various in vitro and clinical studies. They were utilized in various procedures such as management of intrabony defects, gingival recession, furcation defects, extraction socket preservation, and accelerated healing of wound as reviewed by Verma et al in 2017 [68].

Generally, for management of infra-bony defects PRF used either in combination with bone grafts (bovine porous bone mineral, nanocrystalline hydroxyapatite, and demineralized freeze-dried bone allograft [DFDBA]) or pharmacologic agents such as metformin gel was found to be more effective in terms of improvements in clinical parameters and radiographic defect depth reduction compared to when bone grafts or metformin used alone. Also, similar probing depth reduction, clinical attachment level gain, bone fill was observed at sites treated with PRF, or PRF with open flap debridement. Similar to the management of infra-bony defects, the use of PRF in furcation defects when combined with bone grafts (hydroxyapatite) and rosuvastatin has shown better results emphasizing its role in periodontal regeneration $[24,65,69,70]$. PRF has also shown remarkable positive healing effects when used for the preservation of extraction socket and as a sole grafting material in sinus lift procedures during simultaneous dental implantation $[66,71]$.
A recent systematic meta-analysis by Moraschini and Barboza Edos in 2016 have highlighted the inconsistent results of PRF in covering Miller Class I and Class II gingival recessions with no improvement in terms of root coverage, keratinized mucosa width, or clinical attachment level, but it was shown to have increased the gingival thickness and had better wound healing compared to other treatment modalities [72]. The use of PRF with stem cells as endogenous morphogens and fibrin bioscaffolds are under investigation in the field of regenerative endodontic and more recently give a promising result in regeneration of periodontal tissues $[67,73,74]$. Concluding the outcomes of clinical applications reported in literature L-PRF being more users friendly and economic had find wider applications in surgical field to promote wound healing [75]. While i-PRF was suitable injectable form of platelet concentrate to be used when required70. As an alternative to titanium mesh or block bone procedure CGF is known to have higher tensile strength, higher growth factors and higher viscosity than PRF to act as barrier membrane and sticky bone can be good choice for space maintenance, angiogenesis and tension free primary suture in guided bone regeneration $[9,46]$.

\section{Future Research Aspects}

\section{In Vitro Studies}

a) Characterization of PRP and PRF proteomes is highly desired to enable more robust and predictable clinical outcomes.

b) The study of platelet concentrates as controlled release devices, which will allow sustained or even on demand delivery of these growth factor cocktails.

c) Further studies on the effect of autologous platelet concentrates on stem cell behavior, proliferation and differentiation to be used for cell-based therapies.

d) In Vivo Studies and clinical trials

e) We need more data to find the proper therapeutic doses for platelet concentrates suitable for different clinical applications.

f) Development of concrete and practical solutions and not hypothetical benefits including standardized clinical protocols, technologies and delivery systems of platelet concentrates for applications in each era of regenerative medicine.

g) Future clinical trials are now necessary to further investigate the potential of utilizing platelet concentrates for soft tissue regenerative protocols in combination with various biomaterials, pharmaceutical agents or stem cells.

\section{References}

1. Pitaru S, McCulloch CA, Narayanan SA (1994) Cellular origins and differentiation control mechanisms during periodontal development and wound healing. J Periodontal Res 29(2): 81-94.

2. Ahmed TAE, Dare EV, Hincke M (2008) Fibrin: a versatile scaffold for tissue engineering applications. Tissue Eng Part B Rev 14(2): 199-215.

3. Anfossi G, Russo I, Doronzo G, Pomero A, Trovati M, et al. (2010) Adipocytokines in atherothrombosis: focus on platelets and vascular smooth muscle cells. Mediators Inflamm 2010: 174341. 
4. Kobayashi E, Flückiger L, Fujioka-Kobayashi M (2016) Comparative release of growth factors from PRP, PRF, and advanced-PRF. Clin Oral Investig 20(9): 2353-2360.

5. Alsousou J, Thompson M, Hulley P, Noble A, Willett K, et al. (2009) The biology of platelet-rich plasma and its application in trauma and orthopaedic surgery. J Bone Jt Surg 9191(8): 987-996.

6. Marx RE (2004) Platelet-rich plasma: evidence to support its use. J Oral Maxillofac Surg 62(4): 489-496.

7. Marx RE (2001) Platelet-rich plasma (PRP): what is PRP and what is not PRP? Implant Dent 10(4): 225-228.

8. Weibrich G, Kleis WKG, Hafner G, Hitzler WE (2002) Growth factor levels in platelet-rich plasma and correlations with donor age, sex, and platelet count. J Craniomaxillofac Surg 30(2): 97-102.

9. Sushma Naag, Abhishek Savirmath, Butchi Babu Kalakonda, Uday Kiran Uppada, Shekar Kamisetty, et al. (2015) Platelet concentrates: Bioengineering dentistry's regenerative dreams. J Dent Res Rev 2(2): 23-29.

10. Bielecki T, Dohan Ehrenfest DM, Everts PA, Wiczkowski A (2012) The role of leukocytes from L-PRP/L-PRF in wound healing and immune defense: new perspectives. Curr Pharm Biotechnol 13(7): 1153-1162.

11. Dohan Ehrenfest DM, Bielecki T, Jimbo R (2012) Do the fibrin architecture and leukocyte content influence the growth factor release of platelet concentrates? An evidence-based answer comparing a pure platelet-rich plasma (P-PRP) gel and a leukocyte- and platelet-rich fibrin (LPRF). Curr Pharm Biotechnol 13(7): 1145-1152.

12. Sundman EA, Cole BJ, Fortier LA (2011) Growth Factor and Catabolic Cytokine Concentrations Are Influenced by the Cellular Composition of Platelet-Rich Plasma. Am J Sports Med 39(10): 2135-2140.

13. Kobayashi Y, Saita Y, Nishio H (2016) Leukocyte concentration and composition in platelet-rich plasma (PRP) influences the growth factor and protease concentrations. J Orthop Sci 21(5): 683-689.

14. Dohan Ehrenfest DM, Pinto NR, Pereda A (2018) The impact of the centrifuge characteristics and centrifugation protocols on the cells, growth factors, and fibrin architecture of a leukocyte- and platelet-rich fibrin (L-PRF) clot and membrane. Platelets 29(2): 171-184.

15. Dohan Ehrenfest DM, Rasmusson L, Albrektsson T (2009) Classification of platelet concentrates: from pure platelet-rich plasma (P-PRP) to leucocyte- and platelet-rich fibrin (L-PRF). Trends Biotechnol 27(3): 158-167.

16. Matras H (1970) [Effect of various fibrin preparations on reimplantations in the rat skin]. Osterr Z Stomatol 67(9): 338-359.

17. Tawes RL, Sydorak GR, DuVall TB (1994) Autologous fibrin glue: the last step in operative hemostasis. Am J Surg 168(2): 120-122.

18. Rosenthal AR, Egbert PR, Harbury C, Hopkins JL, Rubenstein E, et al. (1978) Use of platelet-fibrinogen-thrombin mixture to seal experimental penetrating corneal wounds. Exp Ophthalmol 207(2): 111-115.

19. Whitman DH, Berry RL, Green DM (1997) Platelet gel: an autologous alternative to fibrin glue with applications in oral and maxillofacial surgery. J Oral Maxillofac Surg 55(11): 1294-1299.

20. Marx RE, Carlson ER, Eichstaedt RM, Schimmele SR, Strauss JE, et al. (1998) Platelet-rich plasma: Growth factor enhancement for bone grafts. Oral Surg Oral Med Oral Pathol Oral Radiol Endod 85(6): 638-646.

21. Mourão $\mathrm{CF}$ de $\mathrm{AB}$, Valiense H, Melo ER, Mourão NBMF, Maia MD-C, et al. (2015) Obtention of injectable platelets rich-fibrin (i-PRF) and its polymerization with bone graft: technical note. Rev Col Bras Cir 42(6): 421-423.

22. Dohan Ehrenfest DM, Bielecki T, Mishra A, (2012) In search of a consensus terminology in the field of platelet concentrates for surgical use: platelet-rich plasma (PRP), platelet-rich fibrin (PRF), fibrin gel polymerization and leukocytes. Curr Pharm Biotechnol 13(7): 11311137.
23. Dohan DM, Choukroun J, Diss A (2006) Platelet-rich fibrin (PRF): a second-generation platelet concentrate. Part I: technological concepts and evolution. Oral Surg Oral Med Oral Pathol Oral Radiol Endod 101(3): e37-44.

24. Choukroun J, Diss A, Simonpieri A (2006) Platelet-rich fibrin (PRF): A second-generation platelet concentrate. Part IV: Clinical effects on tissue healing. Oral Surgery, Oral Med Oral Pathol Oral Radiol Endodontology 101(3): e56-e60.

25. Madurantakam P, Yoganarasimha S, Hasan FK (2015) Characterization of Leukocyte-platelet Rich Fibrin, A Novel Biomaterial. J Vis Exp (103): 1234-1240.

26. Bielecki T, Dohan Ehrenfest DM (2012) Platelet-rich plasma (PRP) and Platelet-Rich Fibrin (PRF): surgical adjuvants, preparations for in situ regenerative medicine and tools for tissue engineering. Curr Pharm Biotechnol 13(7): 1121-1130.

27. Ghanaati S, Booms P, Orlowska A (2014) Advanced platelet-rich fibrin: a new concept for cell-based tissue engineering by means of inflammatory cells. J Oral Implantol 40(6): 679-689.

28. Mourão CF de AB, Valiense H, Melo ER, Mourão NBMF, Maia MD C, et al. (2015) Obtention of injectable platelets rich-fibrin (i-PRF) and its polymerization with bone graft: technical note. Rev Col Bras Cir 42(6): 421-423.

29. Pirpir C, Yilmaz O, Candirli C, Balaban E (2017) Evaluation of effectiveness of concentrated growth factor on osseointegration. Int J Implant Dent 3(1): 7-11.

30. Tunalı M, Özdemir H, Küçükodacı Z, Akman S, Firatlı E, et al. (2013) In vivo evaluation of titanium-prepared platelet-rich fibrin (T-PRF): a new platelet concentrate. Br J Oral Maxillofac Surg 51(5): 438-443.

31. Dohan Ehrenfest DM, Andia I, Zumstein MA, Zhang C-Q, Pinto NR, et al. (2014) Classification of platelet concentrates (Platelet-Rich Plasma-PRP, Platelet-Rich Fibrin-PRF) for topical and infiltrative use in orthopedic and sports medicine: current consensus, clinical implications and perspectives. Muscles Ligaments Tendons J 4(1): 3-9.

32. Ehrenfest DMD, Sammartino G, Shibli JA, Wang H, Zou D, et al. (2013) Guidelines for the publication of articles related to platelet concentrates (Platelet-Rich Plasma - PRP, or Platelet-Rich Fibrin - PRF): the international classification of the POSEIDO. POSEIDO J 1(1): 17-27.

33. Amable PR, Carias RBV, Teixeira MVT (2013) Platelet-rich plasma preparation for regenerative medicine: optimization and quantification of cytokines and growth factors. Stem Cell Res Ther 4(3): 67.

34. Anitua E (2001) The use of plasma-rich growth factors (PRGF) in oral surgery. Pract Proced Aesthet Dent 13(6): 487-493.

35. Magalon J, Bausset O, Serratrice N (2014) Characterization and Comparison of 5 Platelet-Rich Plasma Preparations in a Single-Donor Model. Arthrosc J Arthrosc Relat Surg 30(5): 629-638.

36. Dohan DM, Choukroun J, Diss A (2006) Platelet-rich fibrin (PRF): A second-generation platelet concentrate. Part III: Leucocyte activation: A new feature for platelet concentrates? Oral Surgery, Oral Med Oral Pathol Oral Radiol Endodontology 101(3): e51-e55.

37. Dohan Ehrenfest DM, Del Corso M, Diss A, Mouhyi J, Charrier J-B, et al. (2010) Three-Dimensional Architecture and Cell Composition of a Choukroun's Platelet-Rich Fibrin Clot and Membrane. J Periodontol 81(4): 546-555.

38. Dohan Ehrenfest DM, Pinto NR, Pereda A (2018) The impact of the centrifuge characteristics and centrifugation protocols on the cells, growth factors, and fibrin architecture of a leukocyte- and platelet-rich fibrin (L-PRF) clot and membrane. Platelets 29(2): 171-184.

39. Corso M Del, Toffler M, Dohan Ehrenfest DM (2010) Use of an Autologous Leukocyte and Platelet-Rich Fibrin (L-PRF) Membrane in Post-avulsion Sites: An Overview of Choukroun's PRF. J Implant Adv Clin Dent 1(9): 27-35. 
40. Kobayashi E, Flückiger L, Fujioka Kobayashi M (2016) Comparative release of growth factors from PRP, PRF, and advanced-PRF. Clin Oral Investig 20(9): 2353-2360.

41. Miron RJ, Fujioka Kobayashi M, Hernandez M (2017) Injectable platelet rich fibrin (i-PRF): opportunities in regenerative dentistry? Clin Oral Investig 21(8): 2619-2627.

42. Tunalı M, Özdemir H, Küçükodacı Z, Akman S, Firatlı E, et al. (2013) In vivo evaluation of titanium-prepared platelet-rich fibrin (T-PRF): a new platelet concentrate. Br J Oral Maxillofac Surg 51(5): 438-443.

43. Borsani E, Bonazza V, Buffoli B (2015) Biological Characterization and In Vitro Effects of Human Concentrated Growth Factor Preparation: An Innovative Approach to Tissue Regeneration. Biol Med 7(5).

44. Sohn DS, Huang B, Kim J, Park WE PC (2015) Utilization of autologous concentrated growth factors (CGF) enriched bone graft matrix (sticky bone) and CGF-enriched fibrin membrane in implant dentistry. J Implant Adv Clin Dent 7: 11-18.

45. Upadhayaya V, Arora A, Goyal A (2017) Bioactive Platelet Aggregates: Prp, Prgf, Prf, Cgf And Sticky Bone. IOSR J Dent Med Sci 16(5): 22792861.

46. Agrawal AA (2017) Evolution, current status and advances in application of platelet concentrate in periodontics and implantology. World J Clin cases 5(5): 159-171.

47. Kobayashi M, Kawase T, Okuda K, Wolff LF, Yoshie H, et al. (2015) In vitro immunological and biological evaluations of the angiogenic potential of platelet-rich fibrin preparations: a standardized comparison with PRP preparations. Int J Implant Dent 1(1): 31.

48. Qiao J, An N, Ouyang X (2017) Quantification of growth factors in different platelet concentrates. Platelets 28(8): 774-778.

49. Anitua E, Zalduendo MM, Alkhraisat MH, Orive G (2013) Release kinetics of platelet-derived and plasma-derived growth factors from autologous plasma rich in growth factors. Ann Anat - Anat Anzeiger 195(5): 461466.

50. Masuki H, Okudera T, Watanebe T (2016) Growth factor and proinflammatory cytokine contents in platelet-rich plasma (PRP), plasma rich in growth factors (PRGF), advanced platelet-rich fibrin (A-PRF), and concentrated growth factors (CGF). Int J Implant Dent 2(1): 19.

51. He L, Lin Y, Hu X, Zhang Y, Wu H, et al. (2009) A comparative study of platelet-rich fibrin (PRF) and platelet-rich plasma (PRP) on the effect of proliferation and differentiation of rat osteoblasts in vitro. Oral Surgery, Oral Med Oral Pathol Oral Radiol Endodontology 108(5): 707-713.

52. Amable PR, Teixeira MVT, Carias RBV, Granjeiro JM, Borojevic R, et al (2014) Mesenchymal stromal cell proliferation, gene expression and protein production in human platelet-rich plasma-supplemented media. PLoS One 9(8): e104662.

53. He L, Lin Y, Hu X, Zhang Y, Wu H, et al. (2009) A comparative study of platelet-rich fibrin (PRF) and platelet-rich plasma (PRP) on the effect of proliferation and differentiation of rat osteoblasts in vitro. Oral Surg Oral Med Oral Pathol Oral Radiol Endod 108(5): 707-713.

54. Masoudi E, Leijten JC, Khademhosseini A (2016) Platelet-Rich Blood Derivatives for Stem Cell-Based Tissue Engineering and Regeneration 112(7): 23-30.

55. Cieslik-Bielecka A, Choukroun J, Odin G, Dohan Ehrenfest DM (2012) $\mathrm{L}-\mathrm{PRP} / \mathrm{L}-\mathrm{PRF}$ in esthetic plastic surgery, regenerative medicine of the skin and chronic wounds. Curr Pharm Biotechnol 13(7): 1266-1277.

56. Del Corso M, Vervelle A, Simonpieri A (2012) Current knowledge and perspectives for the use of platelet-rich plasma (PRP) and platelet-rich fibrin (PRF) in oral and maxillofacial surgery part 1: Periodontal and dentoalveolar surgery. Curr Pharm Biotechnol 13(7): 1207-1230.

57. Simonpieri A, Del Corso M, Vervelle A (2012) Current knowledge and perspectives for the use of platelet-rich plasma (PRP) and platelet-rich fibrin (PRF) in oral and maxillofacial surgery part 2: Bone graft, implant and reconstructive surgery. Curr Pharm Biotechnol 13(7): 1231-1256.
58. Pocaterra A, Caruso S, Bernardi S, Scagnoli L, Continenza MA, et al. (2016) Effectiveness of platelet-rich plasma as an adjunctive material to bone graft: a systematic review and meta-analysis of randomized controlled clinical trials. Int J Oral Maxillofac Surg 45(8): 1027-1034.

59. Arora NS, Ramanayake T, Ren Y-F, Romanos GE (2010) Platelet-Rich Plasma in Sinus Augmentation Procedures: A Systematic Literature Review: Part II. Implant Dent 19(2): 145-157.

60. Saleem M, Pisani F, Zahid FM (2018) Adjunctive Platelet-Rich Plasma (PRP) in Infrabony Regenerative Treatment: A Systematic Review and RCT's Meta-Analysis. Stem Cells Int 2018: 9594235.

61. Naik A, Ramesh A, Dwarkanath C, Naik M, Chinnappa A (2013) Use of autologous platelet rich plasma to treat gingival recession in esthetic periodontal surgery. J Indian Soc Periodontol 17(3): 345.

62. Huang L-H, Neiva REF, Soehren SE, Giannobile WV, Wang H-L, et al. (2005) The Effect of Platelet-Rich Plasma on the Coronally Advanced Flap Root Coverage Procedure: A Pilot Human Trial. J Periodontol. 2005;76(10): 1768-1777.

63. Biradar SM, Satyanarayan A, Kulkarni AJ, Patti B, Mysore SK, et al. (2006) Clinical evaluation of the effect of platelet rich plasma on the coronally advanced flap root coverage procedure. Dent Res J (Isfahan) 12(5): 469475 .

64. Weibrich G, Hansen T, Kleis W, Buch R, Hitzler WE (2004) Effect of platelet concentration in platelet-rich plasma on peri-implant bone regeneration. Bone 34(4): 665-671.

65. Simonpieri A, Del Corso M, Vervelle A (2012) Current knowledge and perspectives for the use of platelet-rich plasma (PRP) and platelet-rich fibrin (PRF) in oral and maxillofacial surgery part 2: Bone graft, implant and reconstructive surgery. Curr Pharm Biotechnol 13(7): 1231-1256.

66. Annunziata M, Guida L, Nastri L, Piccirillo A, Sommese L, et al. (2018) The Role of Autologous Platelet Concentrates in Alveolar Socket Preservation: A Systematic Review. Transfus Med Hemotherapy 45(3): 195-203.

67. Fernandes G, Yang S (2016) Application of platelet-rich plasma with stem cells in bone and periodontal tissue engineering. Bone Res 4(1): 16036.

68. Verma UP, Yadav RK, Dixit M (2017) Platelet-rich Fibrin: A Paradigm in Periodontal Therapy - A Systematic Review. J Int Soc Prev Community Dent 7(5): 227-233.

69. Del Fabbro M, Panda S, Jayakumar ND (2014) Autologous platelet concentrates for treatment of periodontal defects. Cochrane Database Syst Rev 5(8): 25-30.

70. Chenchev IL, Ivanova VV, Neychev DZ, Cholakova RB (2017) Application of Platelet-Rich Fibrin and Injectable Platelet-Rich Fibrin in Combination of Bone Substitute Material for Alveolar Ridge Augmentation - a Case Report. Folia Med (Plovdiv) 59(3).

71. Tajima N, Ohba S, Sawase T, Asahina I (2016) Evaluation of sinus floor augmentation with simultaneous implant placement using platelet-rich fibrin as sole grafting material. Int J Oral Maxillofac Implants 28(1): 7783.

72. Moraschini V, Barboza E dos SP (2016) Use of Platelet-Rich Fibrin Membrane in the Treatment of Gingival Recession: A Systematic Review and Meta-Analysis. J Periodontol 87(3): 281-290.

73. Chen Y, Niu Z, Xue Y, Yuan F, Fu Y, Bai N et al. (2014) Improvement in the repair of defects in maxillofacial soft tissue in irradiated minipigs by a mixture of adipose-derived stem cells and platelet-rich fibrin. Br J Oral Maxillofac Surg 52(8): 740-745

74. Wang Z-S, Feng Z-H, Wu G-F (2016) The use of platelet-rich fibrin combined with periodontal ligament and jaw bone mesenchymal stem cell sheets for periodontal tissue engineering. Sci Rep 6: 28126.

75. Miron RJ, Zucchelli G, Pikos MA (2017) Use of platelet-rich fibrin in regenerative dentistry: a systematic review 21(6): 1913-1927. 
ISSN: 2574-1241

DOI: 10.26717/BJSTR.2018.08.001706

ola M Ezzatt. Biomed J Sci \& Tech Res

(c) (9) This work is licensed under Creative BY Commons Attribution 4.0 License

Submission Link: https://biomedres.us/submit-manuscript.php

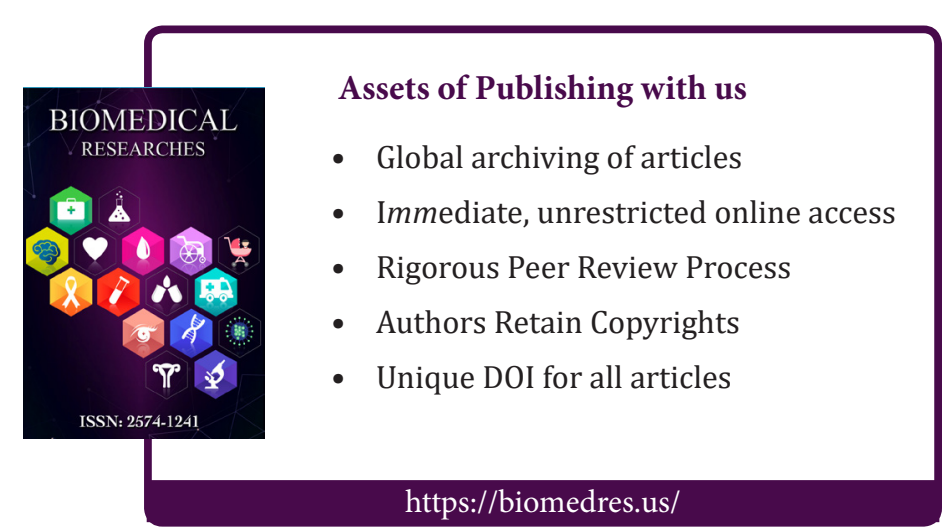

